\section{P2-73 EVALUATION OF BONE FRAGILITY OF JAPANESE WOMEN ACCORDING TO THE RANGE OF AGE: CORRELATION WITH MENOPAUSAL REFERENCE, BONE RELATED INDICATORS AND BIOMARKERS}

doi:10.1136/jech.2011.142976i.8

0 Etsuko, ${ }^{*}$ K Nagato, S Masako, Y Aya, M Daisuke, W Isao, I Kaoru, W Yoshiyuki. Kyoto Prefectural University of Medicine, Kyoto, Japan

Introduction To clarify characteristics of bone fragility in middleaged Japanese women, we have examined the correlation between bone quality by novel ultrasonic bone densitometry system and several biochemical markers of bone turnover.

Methods Subjects are 121 female applied for this study voluntarily. We evaluated which factors are related with bone quality, bone mineral density or bone elastic modulus as fragile risk in healthy Japanese population. We have measured bone metabolism markers (tartrate-resistant acid phosphatase (TRACP)-5b, bone-specific alkaline phosphatase). For the assessment of examined factors, we have divided the subjects into three subgroups according to the age (Group A: <49, Group B: 50-59, Group C: >60) and investigated the correlation of above-mentioned bone fragile index, biomarkers, and the menopausal reference (pre-menopause, peri-menopause, post-menopause).

Results 90 were included in Group A, 21 in Group B and 10 in Group C. Regarding the menopause status, approximately $90 \%$ of subjects in Group A had a menstruation regularly, 25\% of subjects in Group B had a irregular menstruation and $60 \%$ showed the post-menopause. The bone mineral density and bone elastic modulus showed significantly lower in Group C than in Group A or B. The bone-specific alkaline phosphatase and TRACP- $5 \mathrm{~b}$ were significantly higher in Group B and C than in Group A $(p<0.05)$ whereas no statistical differences of these parameters between Group $B$ and $C$ had been noted.

Conclusion The early screening or objective bone check-up analyses by individual are necessary as an initiative medical prevention of osteoporosis and bone fragility in middle-aged women.

\section{P2-74 ALCOHOL CONSUMPTION AND CANCER RISK: A COHORT STUDY IN LITHUANIA}

doi:10.1136/jech.2011.142976i.9

\begin{abstract}
${ }^{1,2} \mathrm{R}$ Everatt, ${ }^{*}{ }^{3} \mathrm{~A}$ Tamosiunas, ${ }^{3} \mathrm{R}$ Radisauskas, ${ }^{1} \mathrm{I}$ Kuzmickiene, ${ }^{3} \mathrm{D}$ Virviciute, ${ }^{3} \mathrm{R}$ Reklaitiene, ${ }^{3} \mathrm{E}$ Milinaviciene, ${ }^{3} \mathrm{G}$ Bernotiene. ${ }^{1}$ Institute of Oncology, Vilnius University, Vilnius, Lithuania; ${ }^{2}$ Institute of Hygiene, Vilnius, Lithuania; ${ }^{3}$ Institute of Cardiology, Academy of Medicine, Lithuanian University of Health Sciences, Kaunas, Lithuania
\end{abstract}

Introduction Alcohol consumption is related to an increased risk of several types of cancer. The evidence for an association with other cancer types remains controversial. Alcohol consumption is common in Lithuania: $40 \%$ of men drank $\geq 60$ g of pure alcohol on a single occasion at least once per month in 2006. Its effect may be reduced significantly by changing the lifestyle. The present study was initiated to assess the relation between alcohol consumption, other behavioural and metabolic risk factors, and cancer risk.

Methods Two cohorts-Kaunas-Rotterdam Intervention Study and Multifactorial Ischaemic Heart Disease Prevention Study - are included. Kaunas-Rotterdam Intervention Study is a WHO-coordinated prospective cohort study of a random sample of 2447 men aged 45-59, living in Kaunas (Lithuania), who took part in a cardiovascular screening programme in 1972-1974. The Multifactorial Ischaemic Heart Disease Prevention Study was carried out in 1976-1980 among 5933 Kaunas men, aged 40-59. All participants underwent physical examination; information on smoking, alcohol consumption, physical activity, etc was obtained via interview.
Study subjects were followed up for 30 years (1978-2008) using National Cancer and Population Registers.

Results Study design will be presented including preliminary results on the relationship between alcohol consumption and cancer risk.

Conclusions The strengths of this study are: the extensive data set from two population-based studies (among the first epidemiological studies carried out in the former Soviet Union); uniform and complete prediagnostic data for exposure factors and possible confounders; and long follow-up. The limitation is the unavailable personal identification numbers in Lithuania in the 1970s.

Funding This research was funded by a grant(No. LIG-07/2010) from the Research Council of Lithuania.

\section{P2-75 HAEMOCHROMATOSIS GENE MUTATIONS IN MOROCCAN PATIENTS WITH CHRONIC VIRAL HEPATITIS B AND C}

doi:10.1136/jech.2011.142976i.10

${ }^{1} \mathrm{~S}$ Ezzikouri, ${ }^{1} \mathrm{~K}$ Rebbani, ${ }^{1} \mathrm{M}$ Ababou, ${ }^{2} \mathrm{R}$ Afifi, ${ }^{2} \mathrm{~A}$ E El Feydi, ${ }^{1} \mathrm{I}$ Brahim, ${ }^{1} \mathrm{~B}$ Kitab, ${ }^{2} \mathrm{M}$ Benazzouz, ${ }^{3} \mathrm{M}$ Kandil, ${ }^{4} \mathrm{~S}$ Nadifi, ${ }^{5} \mathrm{P}$ Pineau, ${ }^{1} \mathrm{~S}$ Benjelloun. ${ }^{7}$ Viral Hepatitis Laboratory, Pasteur Institute, Casablanca, Morocco; ${ }^{2}$ Service de Médecine C, CHU Ibn-Sina, Rabat, Morocco; ${ }^{3}$ Equipe d'Anthropogénétique et Génétique des Populations, Faculté des sciences, Eljadida, Morocco; ${ }^{4}$ Medical Genetic Laboratory and Molecular Pathology, Medical School, Casablanca, Morocco; ${ }^{5}$ eUnité d'Organisation Nucléaire et Oncogenèse, INSERM U579, Institut Pasteur, Paris, France

The implication of haemochromatosis (HFE) gene mutations in chronic viral hepatitis remains controversial. The aim of the present study was to assess the frequencies of the common haemochromatosis gene mutations in Moroccan subjects with chronic viral hepatitis B and C. H63D and C282Y mutations were screened by using polymerase chain reaction followed by restriction fragment length polymorphism analysis in 170 chronic hepatitis B patients, 168 chronic hepatitis C patients and 200 healthy controls. The distribution of allele frequency was then compared between different groups of patients. No subject homozygous for the C282Y mutation was found while $1.76 \%$ and $0 \%$ were heterozygous for this mutation in HBV and HCV patients, that is, rates not statistically different from those observed in healthy control $(2 \%$, $0.129<\mathrm{p}<1.000)$. Similarly, the frequency of the H63D allele was not significantly different between HBV (13.8\%) or HCV $(14.3 \%)$ patients and controls $(13.5 \%, 0.60<\mathrm{p}<0.89)$. Although they do not reach the significance threshold, serum ferritin levels, indicative of body iron content, were higher in HBV or HCV patients than in control individuals with HFE mutations (110.7 \pm 43.61 and $149.67 \pm 43.52 \mathrm{ng} / \mathrm{ml}$ respectively vs $80.84 \pm 21.38 \mathrm{ng} / \mathrm{ml}, 0.229<$ $\mathrm{p}<0.607$ ). In conclusion, in Morocco the frequency of the HFE $\mathrm{C} 282 \mathrm{Y}$ allele is very low and H63D mutation carriage occurs in $<14 \%$ of the subjects, a rate similar in chronic hepatitis patients and control individuals. Thus, we assume that the carriage of the common HFE mutations does not represent a risk factor for evolution towards chronic hepatitis B or C in the genetic and environmental context of North Africa.

\section{P2-76 ANTIBIOTICS FOR HEPATIC ENCEPHALOPATHY: SYSTEMATIC REVIEW OF RANDOMISED CONTROLLED TRIALS}

doi:10.1136/jech.2011.142976i.11

${ }^{1} \mathrm{M}$ Falavigna, ${ }^{*} \mathrm{C}$ Kieling, ${ }^{1} \mathrm{~F}$ Wolff, ${ }^{1} \mathrm{~L}$ Medeiros, ${ }^{1} \mathrm{~L}$ Alves, ${ }^{1,2} \mathrm{H}$ Cheinquer, ${ }^{1} \mathrm{~B}$ Duncan. ${ }^{1}$ UFRGS, Porto Alegre, Brazil; ${ }^{2}$ UFCSPA, Porto Alegre, Brazil

Objective To assess the effectiveness of antibiotics in the treatment of hepatic encephalopathy (HE). 